\title{
Stress states caused in chamber of reinforced concrete grain silo by non-centric emptying on large eccentricities
}

https://doi.org/10.2478/sgem-2018-0043

received September 19, 2018; accepted November 15, 2018.

Abstract: The article presents the analysis of complex stress states in the concrete structure of grain silos, caused by non-centric emptying. The authors present a combination of loads from the pressure of bulk solid on the silo chamber according to Eurocode 1, Part 4 [11], which should be taken into account when emptying on large eccentricities in action assessment class 3 (AAC3) silos. For the example of a cylindrical wheat silo with a height of $25 \mathrm{~m}$ and a diameter of $10 \mathrm{~m}$, the researchers carried out an analysis regarding the impact of the size of the eccentric discharge outlet on the distributions of forces and bending moments in a reinforced concrete wall.

Keywords: stress states; reinforced concrete structure; grain silo; non-centric emptying.

\section{Introduction}

In reinforced concrete grain silos, the emptying phase entails time-variable static and dynamic impacts from the pressure of the bulk solid, which cause complex stress states and major deformations in the concrete wall and the bottom structures. Especially in the case of non-centric emptying on large eccentricities (when the discharge eccentric is larger than half of the radius), the non-symmetrical pressure wave distributions in the silo chamber in the bulk solid flow zone and on the chamber perimeter are not fully recognised. The effect of nonsymmetrical interactions in silos is eccentric tension or

\footnotetext{
*Corresponding author: Jolanta Anna Prusiel, Bialystok University of Technology, Faculty of Civil Engineering and Environmental Engineering, Wiejska 45E, 15-351 Białystok, Poland, E-mail: j.prusiel@pb.edu.pl Krzysztof Gierej: Bialystok University of Technology, Faculty of Civil Engineering and Environmental Engineering, Wiejska 45E, 15-351 Białystok, Poland
}

compression, which contributes to increased local effort and cracks on reinforced concrete walls and, in some cases, may even lead to silo failure. These are important issues in the field of mechanics of engineering structures made of concrete.

The in situ research on exploited objects $[1,2,3]$ and silo models [4], as well as theoretical research $[5,6]$, confirms the occurrence of randomly variable pressure distributions in the silo as a result of eccentric emptying. Analysis of silo failure and disasters $[7,8]$ shows that one of the main causes of failure of these structures, which are designed to be used for at least 100 years [9], is incorrect assumptions regarding the calculation of loads. The results of experimental and theoretical research are applied to improve and expand the methods for determining the impact of bulk solid recommended in the norms [10, 11] and guidelines [12] for the design of silo structures.

To take into account the degree of uncertainty in relation to the accurate determination of the load value, Eurocode 1, Part 4 [11] divides silos into three action assessment classes (AACs; Table 1). Assigning the appropriate class to a silo entails application of simplified or expanded procedures for determining the component values of bulk solid pressure [11, 13]. This initiated extended proceedings for determining the interactions in silos of large mass bulk solid storage and in silos that are filled or emptied on large eccentricities (category AAC3 and category AAC2, respectively). Silos in which the mass of stored material is $>1,000$ tons and is disposed of in large eccentricities $\left(e_{0}>0.25 d_{c}\right)$ need to be assigned to the AAC3 class. Such a case of silo load was not included in the Polish code for the design of reinforced concrete silos [10].

For the example of reinforced concrete cylindrical wheat silo with a diameter of $10 \mathrm{~m}$ and a chamber height of $25 \mathrm{~m}$, emptied non-centrically and classified as AAC3, the influence of the flow channel radius on the redistribution of stresses in reinforced concrete cross-sections of the silo chamber is presented. 
Table 1: Classification of silo action assessment class according to Eurocode 1, Part 4 [11].

\begin{tabular}{|c|c|}
\hline Action assessment class & Class description \\
\hline $\begin{array}{l}\text { Action assessment class } \\
3 \text { (AAC3) }\end{array}$ & $\begin{array}{l}\text { Silo with storage volume of }>10,000 \\
\text { tons. } \\
\text { Silo with storage volume of }>1,000 \\
\text { tons, with any of the following } \\
\text { calculation situations: } \\
\text { a) non-centric emptying at } e_{0} / d_{c}>0.25 \text {; } \\
\text { b) low silos, with the eccentricity of } \\
\text { the upper filling cone } e_{t} / d_{c}>0.25 \text {. }\end{array}$ \\
\hline $\begin{array}{l}\text { Action assessment class } \\
2 \text { (AAC2) }\end{array}$ & $\begin{array}{l}\text { All silos mentioned in Eurocode } 1 \text {, } \\
\text { Part } 4 \text { [11] which are not assigned to a } \\
\text { different class. }\end{array}$ \\
\hline $\begin{array}{l}\text { Action assessment class } \\
1 \text { (AAC1) }\end{array}$ & $\begin{array}{l}\text { Silo with storage volume of }<100 \\
\text { tons. }\end{array}$ \\
\hline
\end{tabular}

\section{Action of bulk solid in} a cylindrical silo of the AAC 3 class during discharge on a large eccentric

In slender silos emptied on large eccentricities $\left(e_{0}>0.25 d_{c}\right)$, which fall into the AAC3 class, it is necessary to take into account two independent cases of load from the pressure of the bulk solid:

1) Increased local pressure (patch load), which is variantly applied at any height (in other zones, there are symmetrical pressures), as shown in Fig. 1.

Increased local pressure (patch load) directed towards the outside of the silo (Fig. 1) is determined based on the following formula:

$$
p_{p e}=C_{p e} \cdot p_{h e}
$$

where $C_{p e}$ is the increasing coefficient during calculation of local pressure during discharge, which depends on the size of the emptying and filling eccentric, chamber geometry and bulk solid properties, $p_{h e}$ is the horizontal pressure on the silo wall during discharge.

Similarly, the component of the local pressure directed inside the silo chamber and operating on the remaining part of the silo's perimeter (Fig. 1) is calculated based on the following formula:

$$
p_{p e i}=\frac{p_{p e}}{7}
$$

2) Pressure, taking into account the geometry of the flow channel (Fig. 2).

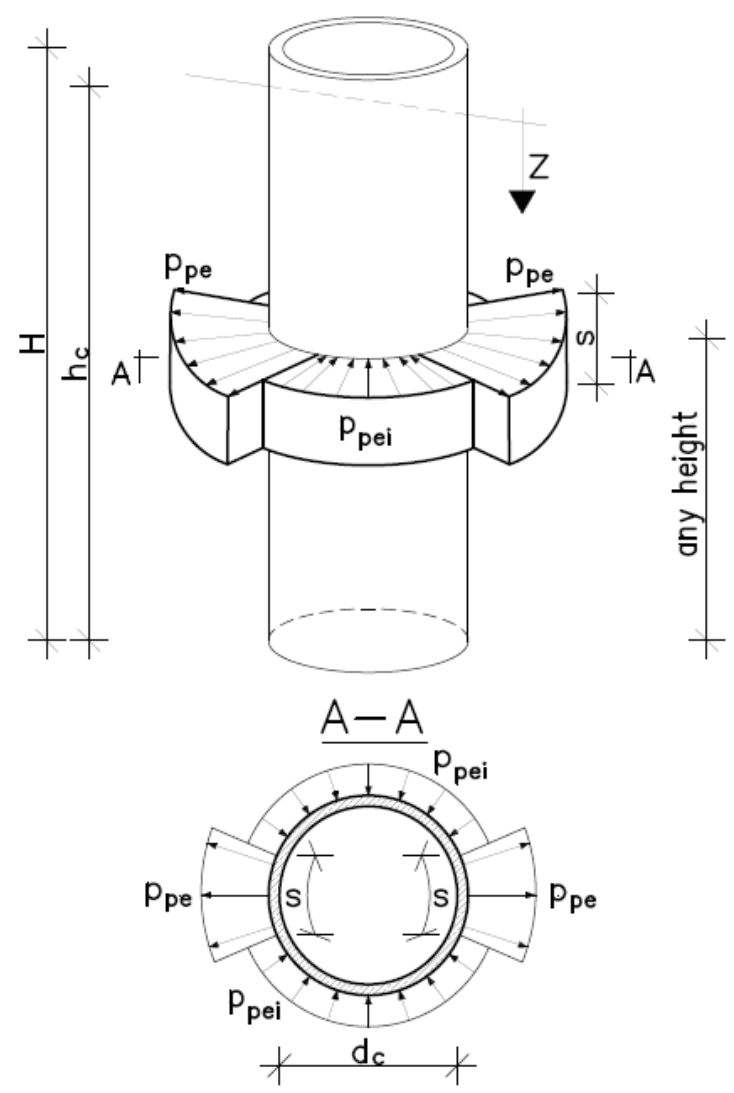

Figure 1: Distribution of local pressure in the cylindrical silo chamber.

Components of pressure in a horizontal crosssection of the ACC3 class silo chamber (Fig. 2), according to Eurocode 1, Part 4 [11], are calculated based on the following formula:

$p_{h c e}=p_{h c o}\left(1-\mathrm{e}^{-\left(z z_{o c}\right)}\right)=\gamma K z_{o c}\left(1-\mathrm{e}^{-\left(z / z_{c \infty}\right)}\right), p_{\text {hse }}=p_{h f}, p_{h a e}=2 p_{h f}-p_{h c e}(3)$

where $p_{h c e}$ is the horizontal pressure in the flow zone, $p_{\text {hse }}$ is the horizontal pressure in the static solid, $p_{\text {hae }}$ is the edge horizontal pressure, $p_{h f}$ is the horizontal pressure after filling the silo, $z$ is the depth measured from the equivalent surface of the material, $z_{o c}$ is the depth characteristic in the Janssen's formula for the channel flow during non-centric emptying and $K$ is the characteristic value of the lateral pressure ratio.

The values of surface friction against the wall are calculated based on the following relation:

$$
p_{\text {wce }}=\mu p_{\text {hce }}, p_{\text {wse }}=p_{\text {wf }}, p_{\text {wae }}=\mu p_{\text {hae }}
$$

where $p_{\text {wce }}$ is the surface friction in the flow zone, $p_{\text {wse }}$ is the friction surface in the static solid, $p_{\text {wae }}$ is the edge 


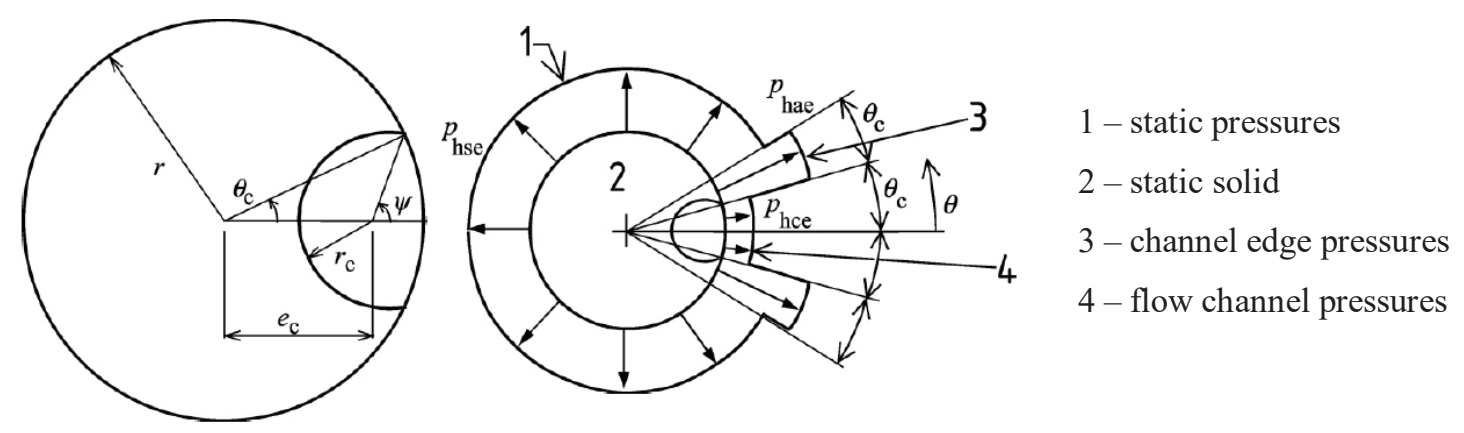

Figure 2: Non-centric flow channel during emptying and the distribution of pressure on the silo wall, according to Eurocode 1, Part 4 [11].

surface friction, $p_{w f}$ is the surface friction after filling the silo, $\mu$ is the coefficient of friction against the vertical wall, $p_{h c e}$ is the horizontal pressure in the flow zone and $p_{\text {hae }}$ is the edge horizontal pressure.

\section{Influence of bulk solid properties on the geometry of the channel flow in the silo}

The geometry of the loose material flow channel in the silo depends on the dimensions of the silo structure and on random parameters, such as variable properties of loose material stored in the silo, uncertainty of the type of flow and the time variability of the pressure distribution on the wall perimeter during emptying. According to Eurocode 1, Part 4 [11], the angle length of the segment where the wall touches the flow channel in the flow zone of the bulk solid is calculated based on the following relation:

$$
\cos \theta_{c}=\frac{r^{2}+e_{c}^{2}-r_{c}^{2}}{2 r e_{c}}
$$

where $r$ is the radius of the silo, $e_{c}$ is the eccentric of location of the flow channel during discharge with large eccentric and $r_{c}$ is the radius of the flow channel (Fig. 2).

The eccentric of the flow channel can be determined based on the following expression:

$e_{c}=r\left[\frac{\mu}{\tan \phi_{i}}\left(1-\frac{r_{c}}{r}\right)+\left(1-\frac{\mu}{\tan \phi_{i}}\right) \sqrt{1-\frac{r_{c}}{r}}\right]=r\left[\frac{\mu}{\tan \phi_{i}}(1-G-\sqrt{1-G})+\sqrt{1-G}\right]$

where $r$ is the radius of the silo, $r_{c}=G r$ is the radius of the flow channel, $\mu$ is the coefficient of friction dependent on the wall category, $\phi_{i}$ is the angle of friction of internal bulk solid stored in the silo, $G$ is the coefficient determining the radius of the flow channel, according to
Eurocode 1, Part 4 [11], the recommended values amount to $0.25,0.4$ and 0.6 .

When applying the above relations, it is necessary to once again calculate the parameters determining the geometry of the flow channel each time the radius of the silo is changed. The Eq. (5) for determining the value of $\cos \theta_{c}$, after appropriate mathematical transformations, can be written in a form that is independent of the radius of the silo:

$$
\cos \theta_{c}=\frac{1+\left(\frac{e_{c}}{r}\right)^{2}+G^{2}}{2 \frac{e_{c}}{r}}=\frac{1+\left[\frac{\mu}{\tan \phi_{i}}(1-G-\sqrt{1-G})+\sqrt{1-G}\right]^{2}+G^{2}}{2\left[\frac{\mu}{\tan \phi_{i}}(1-G-\sqrt{1-G})+\sqrt{1-G}\right]}
$$

Application of Eq. (7), proposed by the authors, at the stage of silo design considerably accelerates and facilitates determination of the distribution of the pressure of the bulk solid in the silo in the case of eccentric emptying on large eccentricities [14]. Table 2 presents the calculated angle values for the selected bulk solids.

By applying the relations represented in Eqs. (3) and (7), the authors determined the values and distributions of wheat pressure in the silo chamber during eccentric emptying for different values of the radius of the flow channel (Fig. 3), adopted in the numerical analysis of the considered silo.

\section{Silo calculation model and assumptions for calculation}

To carry out the analysis of internal forces in the silo chamber wall, the authors created a 3D model of a freestanding silo with height $H=25 \mathrm{~m}$ and diameter $d_{c}=10$ m (Fig. 4a) using the Robot Structural Analysis programme (the "coating design" model). In the analysed 
Table 2: Parameters specifying the geometry of the flow channel (AAC3 class) for the selected bulk solids for reinforced concrete silo wall (D3 wall category, according to Eurocode 1, Part 4 [11]).

\begin{tabular}{|c|c|c|c|c|c|c|c|c|c|c|c|c|c|}
\hline \multirow[t]{2}{*}{ Type of bulk solid } & \multirow[t]{2}{*}{$\mu_{m}$} & \multirow[t]{2}{*}{$a_{\mu}$} & \multirow[t]{2}{*}{$\mu_{d}$} & \multirow[t]{2}{*}{$\phi_{i m}$} & \multirow[t]{2}{*}{$a_{\phi}$} & \multirow{2}{*}{$\phi_{i g}$} & \multirow{2}{*}{$\mu_{d} / \tan \phi_{i g}$} & \multicolumn{3}{|l|}{$e_{c} / r$} & \multicolumn{3}{|c|}{ Angle $\theta_{c}\left[^{\circ}\right]$} \\
\hline & & & & & & & & $G=0.25$ & $G=0.4$ & $G=0.6$ & $G=0.25$ & $G=0.4$ & $G=0.6$ \\
\hline Barley & 0.48 & 1.16 & 0.410 & 28 & 1.14 & 31.92 & 0.658 & 0.790 & 0.660 & 0.479 & 8.9 & 14.8 & 24.9 \\
\hline Corn & 0.53 & 1.12 & 0.470 & 31 & 1.14 & 35.34 & 0.663 & 0.789 & 0.659 & 0.478 & 8.5 & 14.8 & 24.8 \\
\hline Wheat & 0.57 & 1.16 & 0.490 & 30 & 1.12 & 33.6 & 0.738 & 0.780 & 0.646 & 0.461 & 7.7 & 13.3 & 22.3 \\
\hline
\end{tabular}

a)

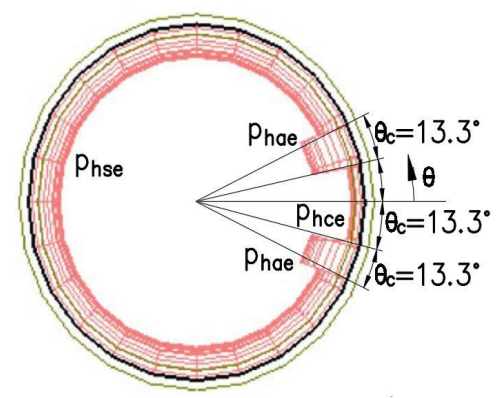

b)

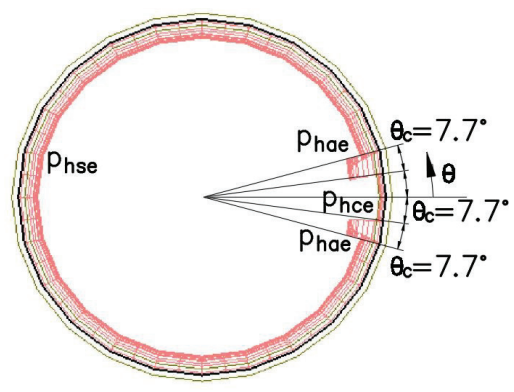

c)

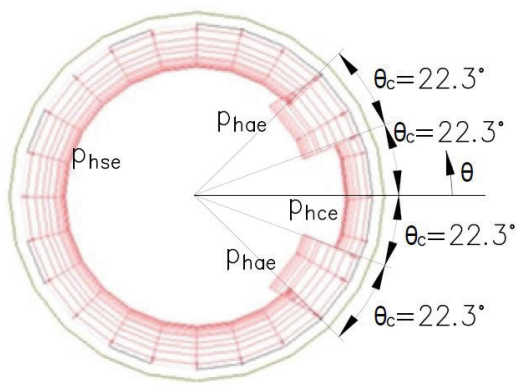

Figure 3: Distribution of pressure on the perimeter of the silo, taking into account a non-centric flow channel while emptying the wheat silo with a diameter of $10 \mathrm{~m}$ : a) $\left.r_{c}=0.25 r, b\right) r_{c}=0.4 r$ and c) $r_{c}=0.6 r$.

silo, the wall was fixed in a circular foundation slab, the cover plate was hinged joined to the chamber wall and the bottom plate was rigidly fixed on the perimeter.

The walls of the silo chamber were modelled in the form of 13 rings with the heights ranging from 2 to $2.375 \mathrm{~m}$. In the programme, a net was generated with mesh dimensions of $0.40 \times 1.31 \mathrm{~m}$. The obtained net was thickened twice at the height of the silo in the area of the appearing local pressure, in the zone of occurrence of the flow channel as well as at the place of connection of the wall with the foundation and the bottom plate of the silo. Data on discretisation of the calculation model of the grain silo is presented in Table 3.

Table 3: Data on discretisation of the silo model (finite element method).

\begin{tabular}{ll}
\hline Number of elements (panels) & $\begin{array}{l}15 \text { (13 wall panels, 1 bottom plate } \\
\text { panel, 1 cover plate panel) }\end{array}$ \\
Number of distribution nodes & 4,030 \\
Standard net dimensions & $40 \mathrm{~cm} \times 131 \mathrm{~cm}$ \\
Thickened net dimensions & $20 \mathrm{~cm} \times 65 \mathrm{~cm}$ \\
$\begin{array}{l}\text { Number of stiff nodes (of edge } \\
\text { elements) }\end{array}$ & 48 \\
\hline
\end{tabular}

Loads from the bulk solid pressure were determined based on Eurocode 1, Part 4 [11], assuming the properties of wheat included in Table 4. Static calculations of the wheat silo were carried out for three sizes of eccentric of the discharge opening: $e_{0(1)}=0.25 d_{c}, e_{0(2)}=0.375 d_{c}$ and $e_{0(3)}=0.5 d_{c}$. The case of small eccentric ( $e_{0(1)}=0.25 d_{c}-$ limit value) was created for the purpose of a comparative analysis of the internal forces in reference to the simplified procedure of determining the pressures on the silo chamber (category AAC2). In the calculations, the authors assumed axial filling of the chamber. The silo wall was loaded with components of the pressure in two combinations:

a) Load combination I-symmetrical horizontal pressure and surface friction in connection with combination of randomly applied local loads on each silo ring respectively (Fig. 5a),

b) Load combination II - non-symmetrical pressure on the chamber perimeter, taking into account the flow channel for three values of the channel radius: $r_{c, 1}=0.25 r, r_{c, 2}=0.4 r$ and $r_{c, 3}=0.6 r$ (Fig. 5b). 
a)

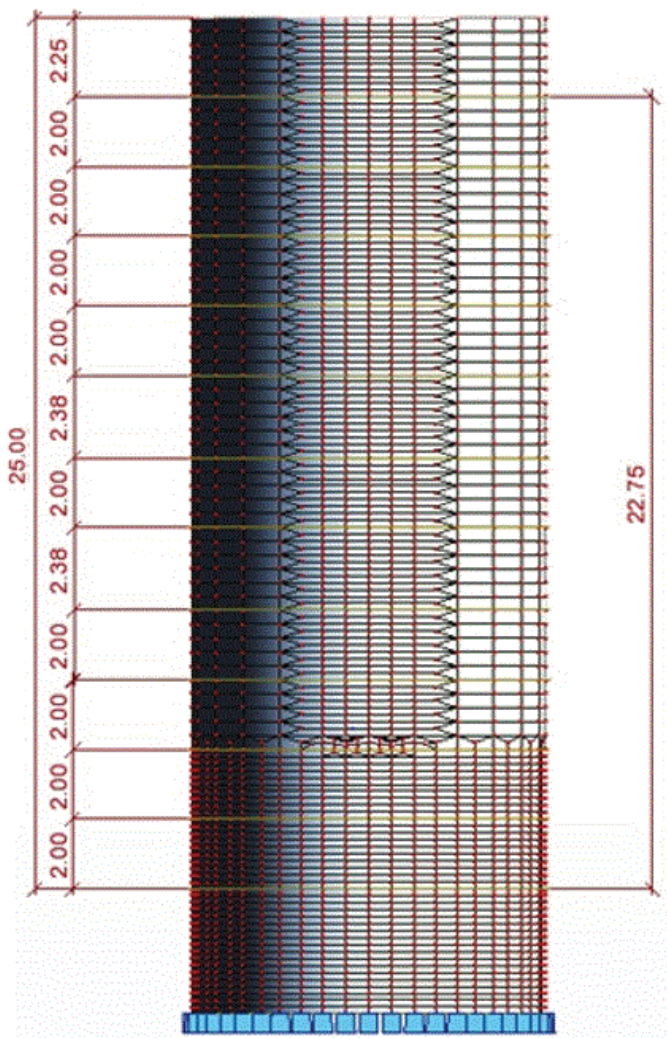

b)

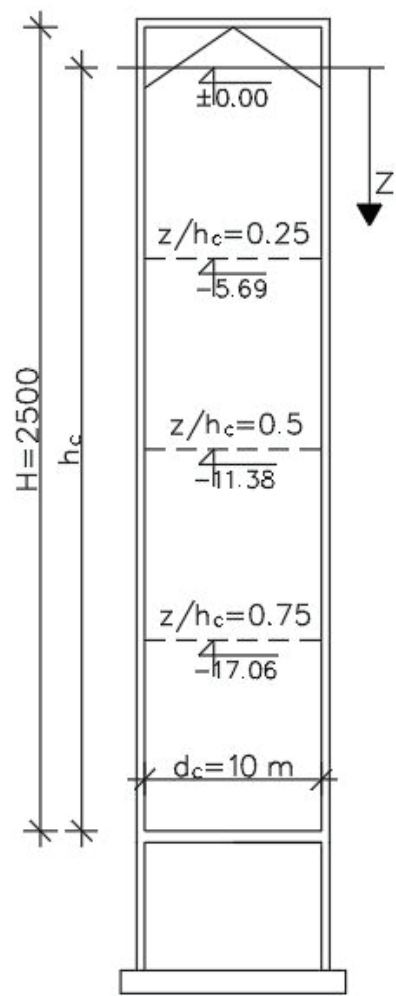

Figure 4: Calculation model of a free-standing silo with height $H=25 \mathrm{~m}$ and diameter $d_{c}=10 \mathrm{~m}$ : a) model of the chamber using the finite element method; and b) levels of reference in the silo adopted for the analysis of internal forces.

Table 4: Physicomechanical properties of wheat adopted to determine the pressure in the silo chamber according to Eurocode 1, Part 4, Annex E[11].

\begin{tabular}{lllll}
\hline Properties of bulk solid & $\begin{array}{l}\text { Wheat } \\
\text { Average value }\end{array}$ & Parameter $\boldsymbol{a}$ & Upper value & Lower value \\
\hline Unit weight, $\gamma\left[\mathrm{kN} / \mathrm{m}^{3}\right]$ & - & - & 9.0 & 7.5 \\
Internal friction angle, $\phi_{i}\left[^{\circ}\right]$ & 30 & 1.12 & 33.6 & 26.8 \\
$\begin{array}{l}\text { Concrete wall friction coefficient, } \mu \\
\text { (D3 wall type) }\end{array}$ & 0.57 & 1.16 & 0.661 & 0.491 \\
Lateral pressure ratio, $K$ & 0.54 & 1.11 & 0.599 & 0.486 \\
Angle of repose, $\phi_{r}\left[^{\circ}\right]$ & 34 & & & \\
Patch load solid reference factor, $C_{o p}$ & 0.5 & & & \\
\hline
\end{tabular}

\section{Analysis of internal forces in the wall during emptying of the silo on large eccentricities}

Based on the results obtained from numerical calculations using the finite element method for a reinforced concrete wheat silo with a height $H=25 \mathrm{~m}$ and internal diameter $d_{c}=10 \mathrm{~m}$ [15], quantitative and qualitative analyses of the internal forces in the wall's cross-sections were carried out. Table 5 presents the extreme values of the vertical and hoop forces, as well as bending moments in both directions in the wall from the symmetrical pressure of the bulk solid in the silo chamber, taking into account the local pressure (Combination I). In the stressed part of the chamber (level $z / h_{c}=0.75$, Fig. 4b) as a result of emptying the silo on a large eccentric $e_{0(3)}=0.5 d_{c}$ in relation to the case of a small eccentric, there was an increase in the hoop force by $15 \%$ and the hoop moment by $83 \%$, while the vertical moment increased three times. 
a)

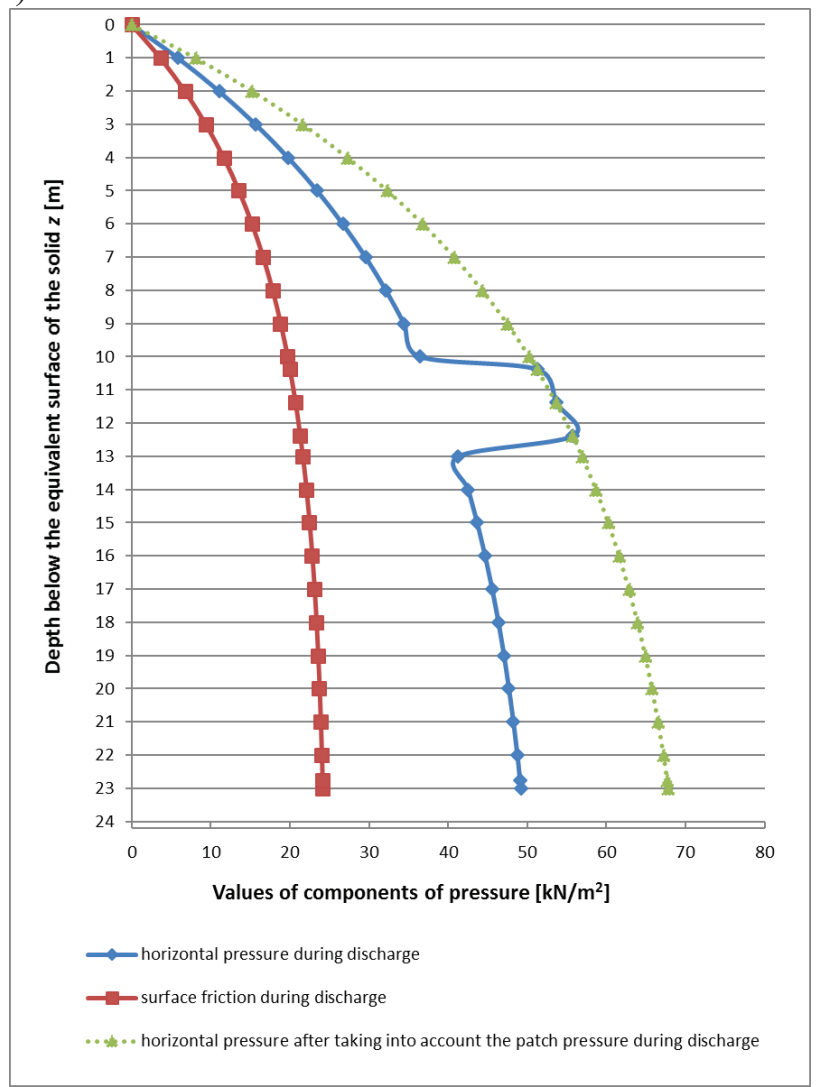

b)

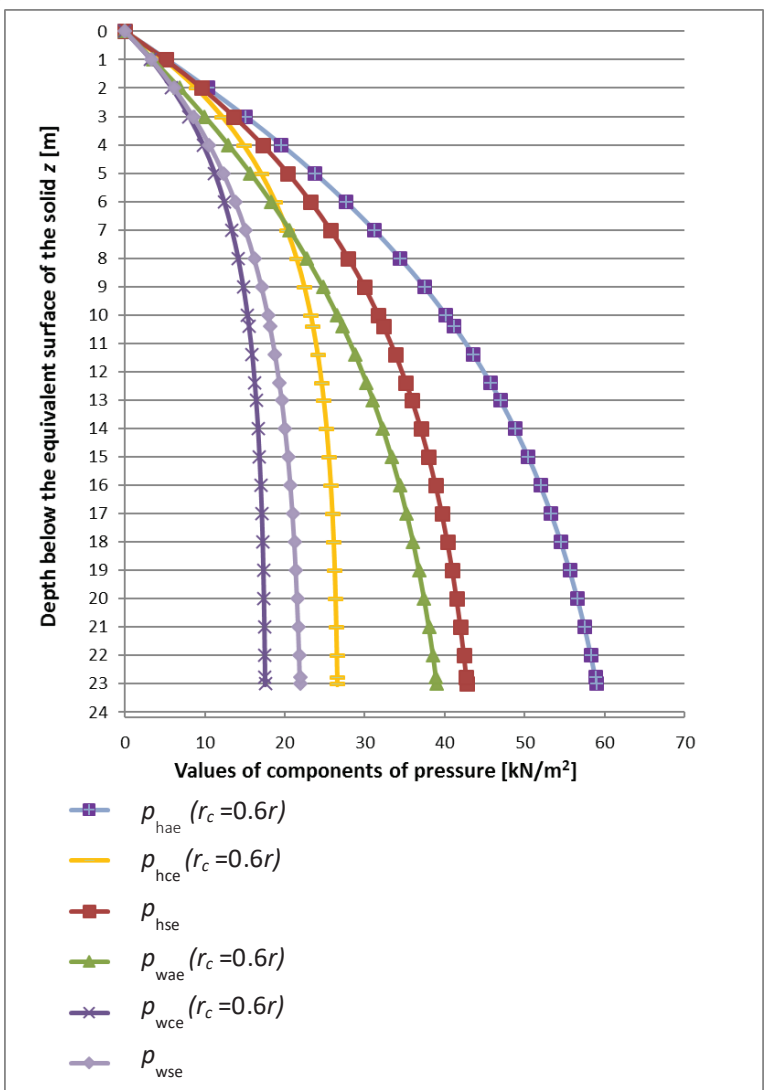

Figure 5: Values of components of bulk solid pressure on the wall of the silo with diameter $d_{c}=10 \mathrm{~m}$ and height $H=25 \mathrm{~m}$ during emptying on large eccentricities $e_{0(2)}=0.375 d_{c}$ : a) Combination I; b) Combination II.

Extreme values of internal forces in the wall obtained taking into account the occurrence of an eccentric flow channel during silo emptying are presented in Table 6. In the case of eccentric emptying, the increase in the radius of the flow channel has a greater impact on the values of vertical forces (maximum differences are 35\%) and a smaller effect on the values of hoop forces (the maximum differences are approximately $12 \%$ ).

Percentage comparison of the calculated hoop moments taking into account the occurrence of the flow channel relative to the values calculated for the eccentricity limit $e_{o(1)}=0.25 d_{c}$ are included in Table 7. Taking into account the occurrence of the flow channel causes a significant increase in hoop moments in relation to the values obtained from local loads with small eccentric emptying. Values of hoop moments at the chamber level $z / h_{c}=0.75$ increase approximately 3.5 times, whereas vertical moments increase almost four times.

Maps of vertical and hoop forces, as well as of hoop moments, in the silo for the case of occurrence of the flow channel specified with the middle angle $\theta_{c}=22.3^{\circ}$, are shown in Fig. 6.

Figs. 7, 8 and 9 compare the distributions of hoop and vertical bending moments, as well as hoop forces, on the perimeter of the chamber in the mid-height region of the silo $\left(z / h_{c}=0.5\right)$ with different dimensions of the radius of the flow channel. The impact of geometry of the flow channel in the case of bending moments is significant, because with the largest radius $r_{c, 3}=0.6 r$, the values of the hoop and vertical moment increased approximately two times in relation to the values of the moments with the smallest radius of the flow channel $r_{c, 1}=0.25 r$. In the horizontal cross-section of the wall (Figs. 7 and 8), one can also notice bending moments with opposite signs. This is due to the occurrence of variable values of pressure on the perimeter of the silo in the area of non-centric flow channel (Fig. 3).

Compilation of the diagrams of hoop and vertical moments in the vertical cross-sections of the wall calculated taking into account the occurrence of the flow 
Table 5: Extreme values of internal forces in the wall of the silo with diameter $d_{c}=10 \mathrm{~m}$ at selected levels from symmetrical pressure, taking into account the local load.

\begin{tabular}{lllll}
\hline Values of internal forces & Level $z / h_{c}$ & \\
& & 0.25 & 0.5 & 0.75 \\
\hline$N[\mathrm{kN} / \mathrm{m}]$ & $e_{0(1)}=0.25 d_{c}$ & -128.93 & -267.79 & -417.14 \\
& $e_{0(2)}=0.375 d_{c}$ & -137.93 & -276.44 & -426.79 \\
& $e_{0(3)}=0.5 d_{c}$ & -146.39 & -284.68 & -431.66 \\
$R[\mathrm{kN} / \mathrm{m}]$ & $e_{0(1)}=0.25 d_{c}$ & 126.82 & 213.18 & 228.26 \\
& $e_{0(2)}=0.375 d_{c}$ & 139.09 & 221.04 & 253.38 \\
& $e_{0(3)}=0.5 d_{c}$ & 144.14 & 232.03 & 263.44 \\
$M_{\mathrm{N}}[\mathrm{kNm} / \mathrm{m}]$ & $e_{0(1)}=0.25 d_{c}$ & 0.76 & 2.9 & 1.46 \\
& $e_{0(2)}=0.375 d_{c}$ & 1.83 & 3.61 & 3.57 \\
& $e_{0(3)}=0.5 d_{c}$ & 2.32 & 4.61 & 4.47 \\
$M_{\mathrm{R}}[\mathrm{kNm} / \mathrm{m}]$ & $e_{0(1)}=0.25 d_{c}$ & 4.43 & 9.05 & 6.76 \\
& $e_{0(2)}=0.375 d_{c}$ & 6.28 & 10.42 & 10.61 \\
& $e_{0(3)}=0.5 d_{c}$ & 7.31 & 12.34 & 12.42 \\
\hline
\end{tabular}

Table 6: Extreme values of internal forces in the wall of the silo with the diameter $d_{c}=10 \mathrm{~m}$ emptied on a large eccentric taking into account the occurrence of non-centric flow channel.

\begin{tabular}{lllll}
\hline Values of internal forces & \multicolumn{3}{l}{ Level $z / h_{c}$} & \\
& & 0.25 & 0.5 & 0.75 \\
\hline$N[\mathrm{kN} / \mathrm{m}]$ & $G=0.25$ & -97.51 & -232.55 & -398.24 \\
& $G=0.4$ & -112.27 & -254.48 & -433.87 \\
& $G=0.6$ & -131.26 & -308.19 & -487.33 \\
$R[\mathrm{kN} / \mathrm{m}]$ & $G=0.25$ & 101.05 & 165.67 & 195.77 \\
& $G=0.4$ & 113.35 & 173.13 & 201.99 \\
$M_{\mathrm{N}}[\mathrm{kNm} / \mathrm{m}]$ & $G=0.6$ & 113.5 & 173.39 & 205.98 \\
& $G=0.25$ & -1.09 & -2.31 & -2.89 \\
& $G=0.4$ & -1.7 & -3.39 & -4.33 \\
$M_{\mathrm{R}}[\mathrm{kNm} / \mathrm{m}]$ & $G=0.6$ & -2.39 & -4.65 & -5.58 \\
& $G=0.25$ & -5.78 & -11.34 & -13.89 \\
& $G=0.4$ & -8.54 & -16.34 & -19.91 \\
& $G=0.6$ & -11.47 & -20.82 & -23.05 \\
\hline
\end{tabular}

channel have been shown in Fig. 10 (flow channel: crosssection $\mathrm{A}-\mathrm{A}$; channel edge: cross-section $\mathrm{B}-\mathrm{B})$.

In the case of combination of symmetrical pressure with local load, the researchers obtained higher values of hoop forces than when taking into account the occurrence of the flow channel (maximum differences are approximately $22 \%$ ). On the other hand, creation of noncentric flow channel causes higher values of hoop and vertical moments in the silo wall than in the case of local loads.

\section{Conclusions}

Based on the multivariant numerical analysis of the complex (as well as static and dynamic random variables) load conditions of a cylindrical reinforced concrete wheat silo emptied on large eccentric (silo category AAC3), the authors formulated the following conclusions:

- Increasing the radius of the flow channel of the bulk solid in the silo causes local increases of both horizontal pressure and surface friction of the bulk solid in the flow zone.

- Redistribution of stresses in the silo wall under the influence of non-centric emptying, together with creation of the flow channel on a large eccentric, results in multiple increases of values of hoop and vertical moments in the silo wall in relation to emptying on a small eccentric.

- The eccentric of the flow channel during emptying of the silo on large eccentricities does not depend on the size of the eccentric of the discharge outlet (according to the procedure accepted in the Eurocode 1, Part 4).

- During side discharge of the bulk solid in the silo (eccentric of the discharge outlet equal to half of the diameter of the chamber), the method of determining non-symmetrical pressure raises doubts related to occurrence of underestimation of locally increased pressure of the bulk solid in the silo chamber.

Table 7: Percentage comparison of values of hoop moments in the silo with the diameter $d_{c}=10 \mathrm{~m}$, calculated taking into account the occurrence of flow channel with values calculated on the eccentricity limit $e_{0(1)}=0.25 d_{c}$.

\begin{tabular}{llllllll}
\hline Level, $\boldsymbol{z} / \boldsymbol{h}_{\mathrm{c}}$ & \multicolumn{2}{l}{ Values of hoop moments, $\boldsymbol{M}_{\mathrm{R}}[\mathrm{kNm} / \mathrm{m}]$} & & & & \\
& $\boldsymbol{e}_{0(1)}=\mathbf{0 . 2 5} \boldsymbol{d}_{\boldsymbol{c}}$ & $\boldsymbol{G}=\mathbf{0 . 2 5}$ & $\%$ & $\mathbf{G}=\mathbf{0 . 4}$ & $\%$ & $\mathbf{G}=\mathbf{0 . 6}$ & $\%$ \\
\hline 0.25 & 4.43 & -5.78 & $\mathbf{3 0 . 5}$ & -8.54 & $\mathbf{9 2 . 8}$ & -11.47 & $\mathbf{1 5 8 . 9}$ \\
0.5 & 9.05 & -11.34 & $\mathbf{2 5 . 3}$ & -16.34 & $\mathbf{8 0 . 6}$ & -20.82 & $\mathbf{1 3 0 . 1}$ \\
0.75 & 6.76 & -13.89 & $\mathbf{1 0 5 . 5}$ & -19.91 & $\mathbf{1 9 4 . 5}$ & -23.05 & $\mathbf{2 4 1 . 0}$ \\
\hline
\end{tabular}


a)

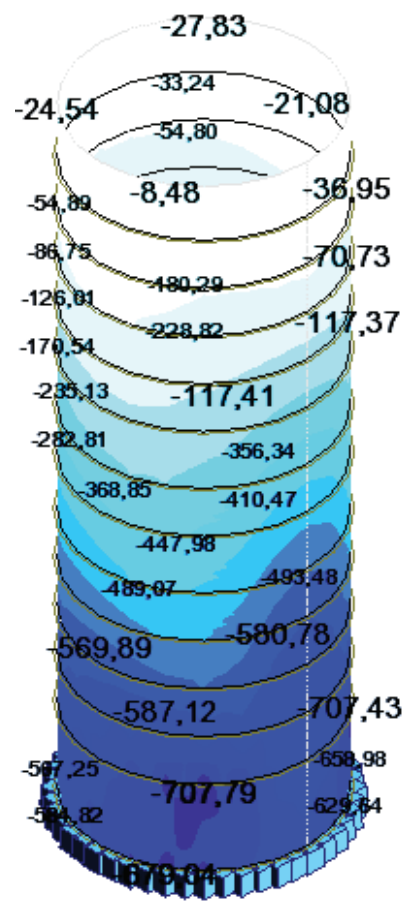

b)

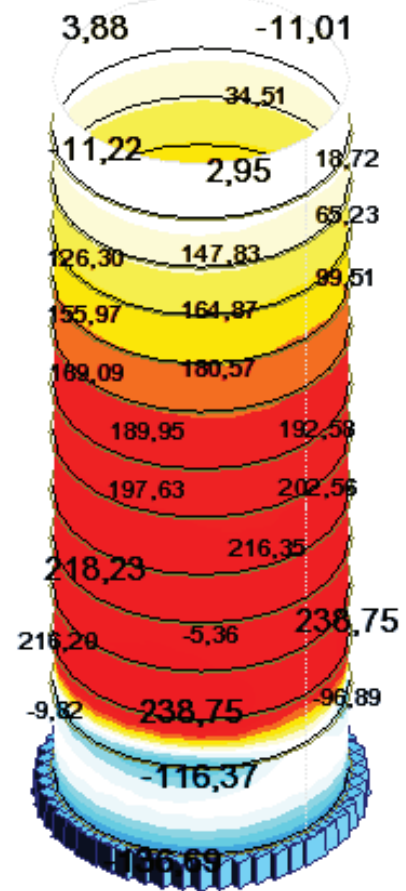

c)

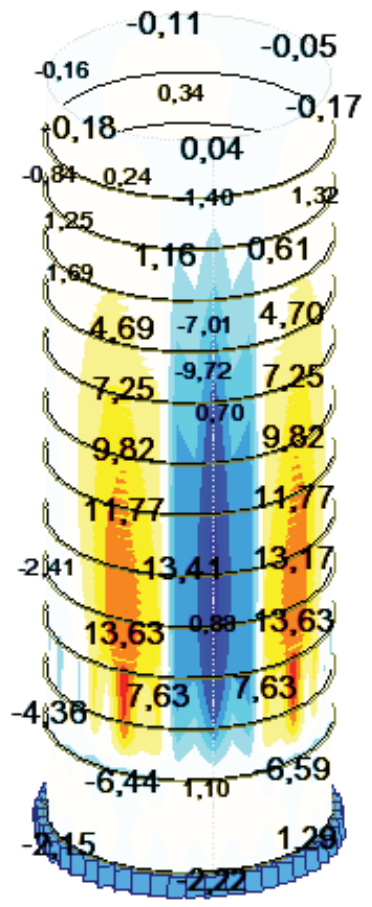

Figure 6: Maps of internal forces during emptying of the silo with the diameter $d_{c}=10 \mathrm{~m}$ on a large eccentric taking into account the occurrence of non-centric flow channel with the radius $r_{c, 3}=0.6 r\left(\theta_{c}=22.3^{\circ}\right): a$ ) maps of vertical forces, $N[\mathrm{kN} / \mathrm{m}]$; b) maps of hoop forces, $R[\mathrm{kN} / \mathrm{m}]$; and c) maps of hoop moments, $M_{\mathrm{R}}[\mathrm{kNm} / \mathrm{m}]$.

1)

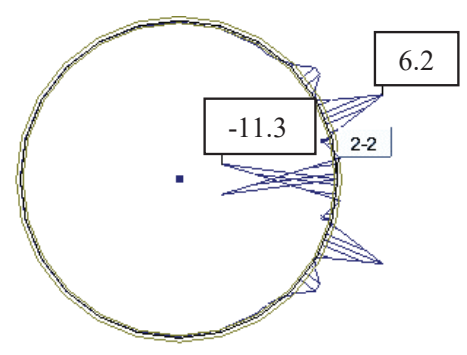

2)

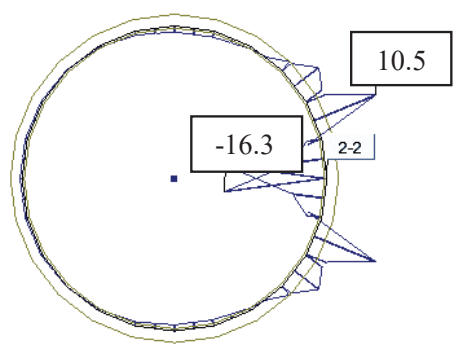

3)

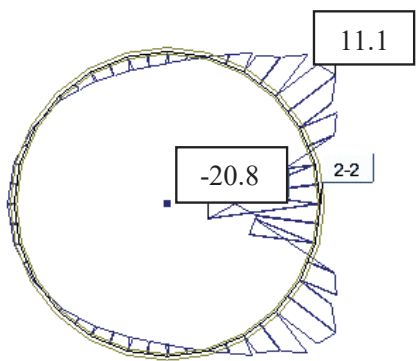

Figure 7. Diagrams of hoop moments, $\left.\left.M_{R}, \mathrm{kNm} / \mathrm{m}\left(z / h_{c}=0.5\right): 1\right) \mathrm{G}=0.25,2\right) \mathrm{G}=0.4$ and 3) $G=0.6$.

1)

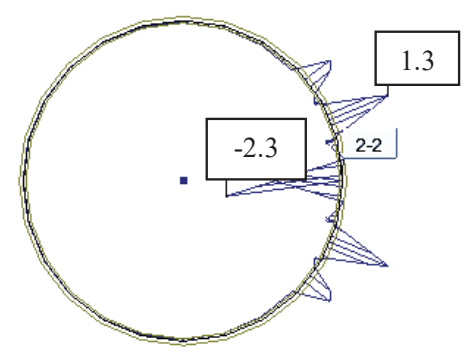

2)

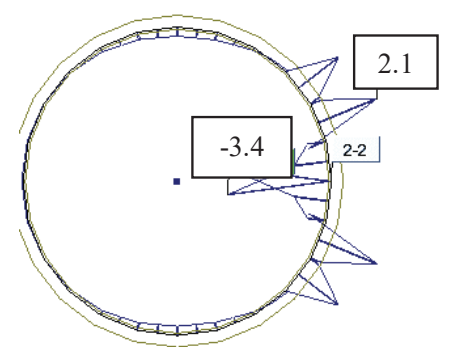

3)

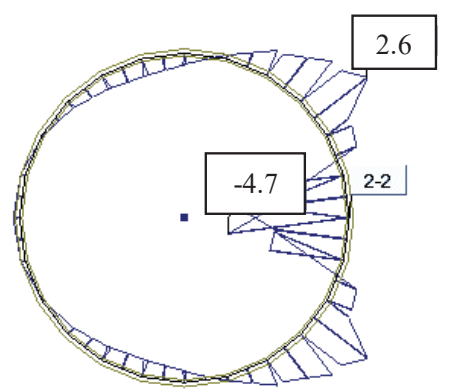

Figure 8: Diagrams of vertical moments, $\left.\left.M_{N}, k N m / m\left(z / h_{c}=0.5\right): 1\right) G=0.25,2\right) G=0.4$ and 3) $G=0.6$. 
1)

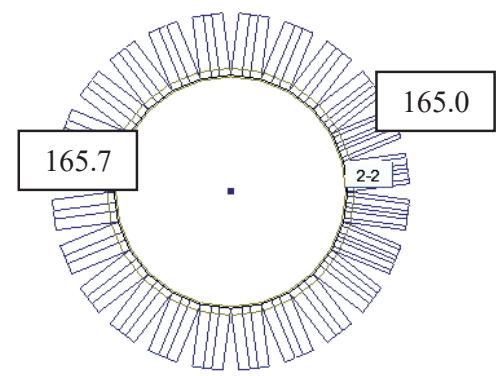

2)

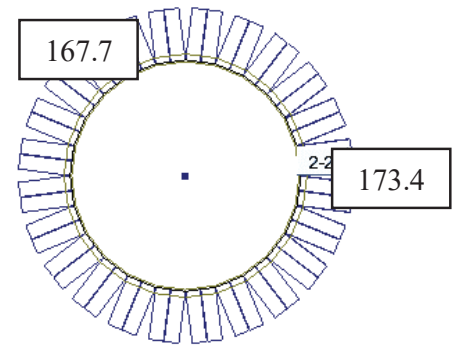

3)

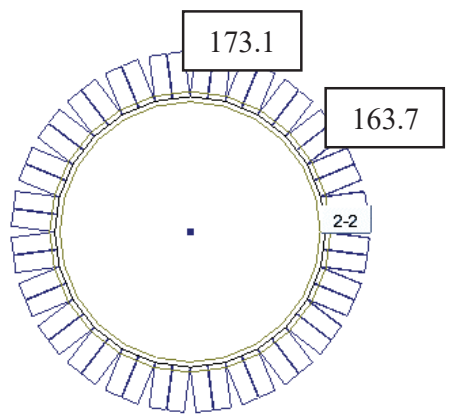

Figure 9: Diagrams of hoop forces, $\left.\left.R, \mathrm{kN} / \mathrm{m}\left(z / h_{c}=0.5\right): 1\right) \mathrm{G}=0.25,2\right) G=0.4$ and 3) $G=0.6$.

a)

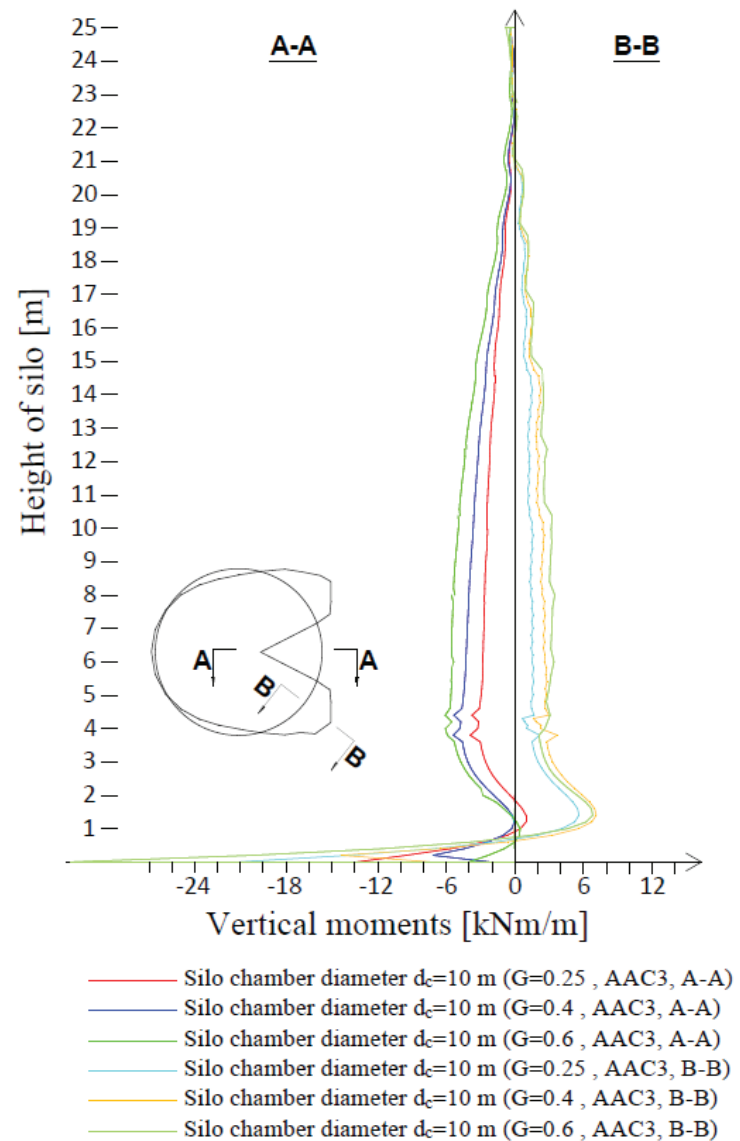

b)

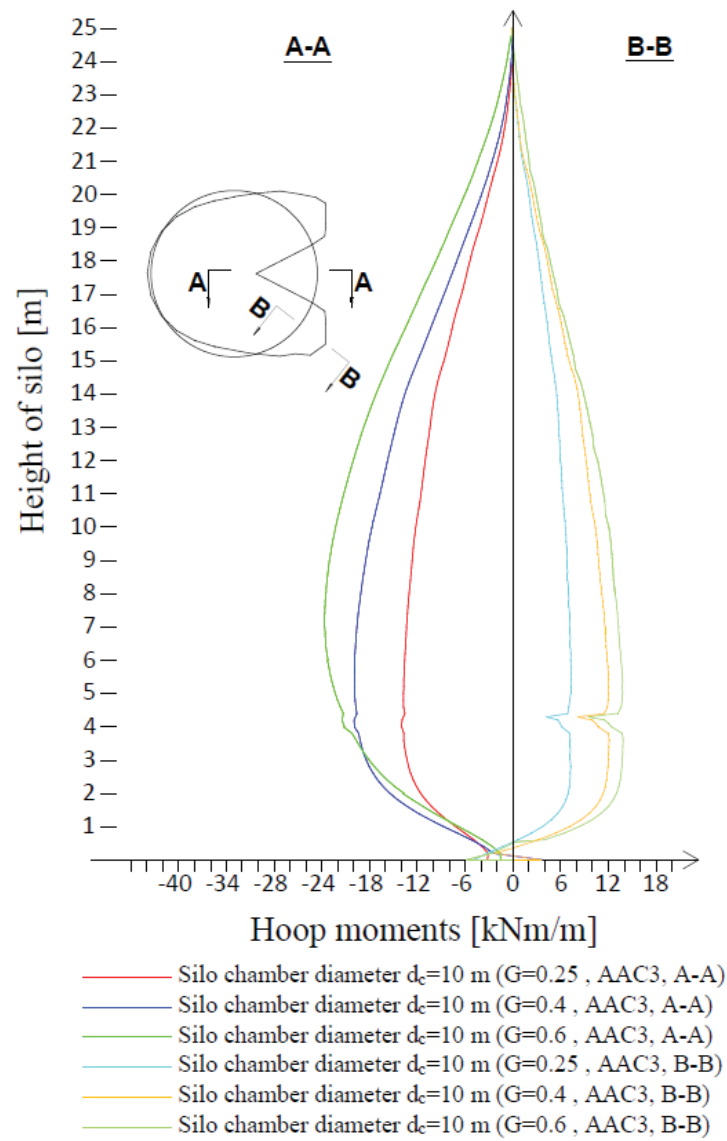

Figure 10: Diagrams of moments in the silo wall calculated taking into account the occurrence of the flow channel: a) vertical moments; and b) hoop moments.

Therefore, it is necessary to conduct experimental research on exploited silos and theoretical analyses on numerical models of silos emptied non-centrically on large eccentricities, in order to verify the methods of calculating non-symmetrical pressure of bulk solid and thereafter determine the complex stress states in the concrete structure of silos, which will affect their reliability.
Acknowledgement: This paper was prepared at the Bialystok University of Technology within the framework of the S/WBiIS/2/2017 project sponsored by the Ministry of Science and Higher Education, Białystok, Poland. 


\section{References}

[1] Kamiński, M. (1986). The Study of the Pressure Exerted by Cohesionless Bulk Solids on the Walls of a Containing Vessel (silo). Releases of the Wroclaw University of Technology, Wroclaw, (in polish).

[2] Łapko, A. (2010). Pressure of agricultural bulk solids under eccentric discharging of cylindrical concrete silo bin. International Agrophysics, 24(1), 51-56.

[3] Łapko, A., Wójcik, R. (2004). Analysis of eccentric discharging effects on stress states in cylindrical silo bins for grain. Acta Agrophysica, 4(2), 393-405, (in polish).

[4] Molenda, M., Horabik, J., Thompson, S.A., Ross, I.J. (2000). Asymmetry of grain bin loads induced by non-axial filling and discharge. In: XI Conference "Reinforced Concrete and Compressed Tanks for Bulk and Liquid Materials", Świeradów Zdrój, 143-150, (in polish).

[5] tapko, A., Prusiel, J.A. (2004). Structural analysis of RC circular grouped silos under patch actions. Granular Matter, 6(2-3), 185-190.

[6] Safarian, S.S. (2001). Empirical method for computing bending moments in circular silo walls due to asymmetric flow considering flow channel concept. Bulk Solid Handling, 21(3-4), 153-155.

[7] Martens, P. (1988). Silo-Handbuch. Wilhelm Ernst \& Sohn Verlag für Architektur und technische Wissenschaften, Berlin.

[8] Runkiewicz, L. (2012). Analysis of hazards, failures and disasters involving reinforced concrete tanks and silos. Construction Review, 4, 75-79, (in polish).

[9] PN-EN 1990:2004 Eurocode. Basic design rules of structures, (in polish).

[10] PN-B-03262:2002 Reinforced concrete silos for bulk materials. Static calculations, design, construction and exploitation, (in polish).

[11] EN 1991-4:2006 Eurocode 1. Actions on structures. Part 4: Silos and tanks.

[12] Borcz, A., Maj, M., Trochanowski, A. (1999). Guiding Principles of Silo Designing, Construction, and Operation. Scientific papers of the Institute of Building of Wroclaw Technical University Monografie, Wroclaw, Z. 61, (in polish).

[13] Halicka, A., Franczak, D. (2011). Designing Reinforced Concrete Tanks. T.1. Containers for Bulk Solids. PWN, Warsaw, (in polish).

[14] Prusiel, J.A., Gierej, K. (2016). Determination of the flow channel parameters in the silos subject to eccentric discharge. Construction Materials, 5(525), 107-108, (in polish).

[15] Gierej, K. (2015). A numerical analysis of cylindrical silo emptied eccentrically. Master's thesis, Bialystok University of Technology, Bialystok, (in polish). 